e-ISSN 2774-4671

Vol. 1 Nomor 2

Tahun 2021

Hal. 61 - 71

JURNAL ILMIAH KEBIDANAN

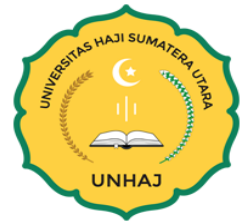

\title{
PENGARUH PRENATAL YOGA DENGAN KUALITAS TIDUR IBU HAMIL TRIMESTER III DI UPTD PUSKESMAS AEK LOBA TAHUN 2021
}

\author{
Maidina Putri ${ }^{1}$, Hidayah Nur ${ }^{2}$ \\ ${ }^{1}$ STIKes As Syifa Kisaran, Indonesia \\ ${ }^{2}$ STIKes As Syifa Kisaran, Indonesia \\ maidinaputri@ymail.com ${ }^{1}$, nurh02924@gmail.com ${ }^{2}$
}

\begin{abstract}
ABSTRAK
Latar Belakang : Ibu hamil trimester III adalah masa penentu untuk menyiapkan tubuh menghadapi persalinan. banyak ibu hamil yang kesulitan tidur karena stress, aktifitas janin atau karena perut yang semakin memebesar sehingga teras akurang nyaman. Yoga adah cara baik untuk meningkatkan kualitas tidur. berlatih yoga akan membantu ibu hamil untuk rileks sehingga bebas dari berbagai keluhan ketidaknyamanan dan meningkatkan kualitas tidur Tujuan Penelitian :Untuk mengetahui Pengaruh Prenatal Yoga dengan Kualitas Tidur Ibu hamil Trimester III di UPTD Puskesmas Aek Loba Tahun 2021.Metode : dengan metode Pre eksperimen one group pre post test design. Penelitian dengan rancangan sekelompok subjek diberi intervensi tanpa ada pembanding. Penelitian ini dilaks anakan di UPTD Puskesmas Aek Loba sebanyak 30 responden. Teknik sampling menggunakan total sampling. Variabel independen adalah Pengaruh Prenatal Yoga,sedangkan variabel dependen adalah kualitas tidur ibu hamil trimester III .instrumen penilaian menggunakan PSQI dan observasi, analisis menggunakan uji wilcox on Hasil : analisis data diperoleh nilai $p$-value sebesar $0,000<0,05(\mathrm{p}$ $=0,000<0,05)$ yaitu Ha diterima. Dengan demikian, dapat disimpulkan bahwa adanya pengaruh Prenatal Yoga terhadap kualitas tidur ibu hamil trimester III di UPTD Puskesmas Aek Loba. Diharapkan ibu hamil trimester III dapat meningkatkan kualitas tidurnya salah satunya dengan menerapkan senam yoga selama kehamilan dengan melakukan gerakan pemanas an, gerakan inti, relaksasi nafas dan afirmasi fositif terbimbing yang dilakukan secara teratur minimal $1 \mathrm{x}$ seminggu
\end{abstract}

Kata Kunci : Kualitas tidur, Prenatal yoga, Ibu hamil 
e-ISSN 2774-4671

Vol. 1 Nomor 2

Tahun 2021

Hal. 61 - 71

JURNAL ILMIAH KEBIDANAN

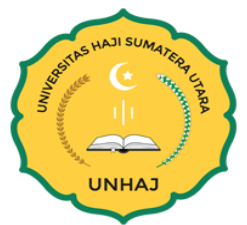

\title{
INFLUENCE OF PRENATAL YOGA WITH SLEEP QUALITY OF PREGNANT WOMEN IN TRIMESTER III IN UPTD PUSKESMAS AEK LOBA IN 2021
}

\author{
Maidina Putri ${ }^{1}$, Hidayah Nur ${ }^{2}$ \\ ${ }^{1}$ STIKes As Syifa Kisaran, Indonesia \\ ${ }^{2}$ STIKes As Syifa Kisaran, Indonesia \\ maidinaputri@ymail.com ${ }^{1}$, nurh02924@gmail.com ${ }^{2}$
}

\begin{abstract}
Background: The third trimester of pregnancy is a decisive period to prepare the body for childbirth. Many pregnant women have difficulty sleeping because of stress, fetal activity or because the stomach is getting bigger so it feels less comfortable. Yoga is a great way to improve sleep quality. practicing yog a will help pregnant women to relax so that they are free from various complaints of discomfort and improve sleep quality

Research Objectives: To determine the effect of Prenatal Yoga on the sleep quality of third trimester pregnant women at UPTD Puskesmas Aek Loba in 2021. Method: Pre-experimental method one group pre post test design Research with a group design of subjects was given an intervention without any comparison. This research was conducted at the UPTD Puskesmas Aek Loba as many as 30 respondents. The sampling technique used total sampling. The independent variable was the influence of Prenatal Yoga, while the dependent variable was the sleep quality of pregnant women in the third trimester. The assessment instrument used the PSQI and observation, the analysis used the Wilcoxon test. Results: data analysis obtained pvalue of $0.000<0.05(p=0.000<0.05)$ that is Ha is accepted. Thus, it can be concluded that there is an effect of Prenatal Yoga on the sleep quality of third trimester pregnant women at UPTD Puskesmas Aek Loba. It is expected that third trimester pregnant women can improve the quality of their sleep, one of which is by applying yoga exercises during pregnancy by doing warm-up movements, core movements, breath relaxation and guided positive affirmations which are carried out regularly at least once a week
\end{abstract}

Keywords: Sleep quality, Prenatal yoga, Pregnant 
e-ISSN 2774-4671

Vol. 1 Nomor 2

Tahun 2021

Hal. 61 - 71
JID A N

JURNAL ILMIAH KEBIDANAN

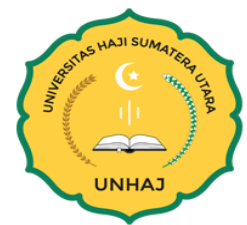

\section{Pendahuluan}

Masa kehamilan merupakan saat istimewa seorang wanita dengan harapan kelahiran yang lembut, nyaman, dan membahagiakan. Berlatih yoga pada masa ini merupakan salah satu solusi self help yang akan menunjang proses kehamilan, kelahiran, dan bahkan pengasuhan anak. Yoga bagi kehamilan memfokuskan perhatian pada ritme napas, mengutamakan kenyamanan serta keamanan dalam berlatih sehingga memberikan manfaat. (Shindu,2014)

Permasalahan pada kehamilan trimester ketiga sering muncul hingga mengganggu aktifitas maupun kualitas tidur atau is tirahat dari ibu hamil ters ebut.Permasalahan yang sering terjadi misalkan nyeri punggung bawah, penurunan jumlah tidur (insomnia), pegalpegal, letih, sesak nafas, mudah emosi, rasa khawatir, kecemasan, sering buang air kecil, gelisah, tidak mampu memusatkan perhatian dan ragu-ragu (Shindu, 2014).

Menurut data WHO (World Health Organization) tahun 2014 kelas ibu hamil terbukti dapat mengurangi angka kematian ibu, karena dengan mengikuti kelas ibu hamil dapat mengetahui kondisi kehamilan dan mencegah masalah kehamilan yang terjadi pada ibu hamil, WHO menjelaskan bahwa sekitar 287.000 ibu meninggal karena komplikasi kehamilan dan kelahiran anak, seperti perdarahan 28\%, preeklampsi/eklampsi $24 \%$, infeksi $11 \%$, dan penyebab tidak langsung (trauma obstetri) $5 \%$, dan sebagian besar kasus kematian ibu di dunia terjadi di negara-negara berkembang (Nugroho, 2017)

Menurut National Sleep Foundation (2017)sekitar 70 juta orang amerika mengalami masalah tidur .Sebanyak $78 \%$ wanita mengalami gangguan tidur selama kehamilan terutama pada trimester III (Sri ,2018). Adapun ketidak nyamanan fisuk yang sering di alami wanita berupa kram kaki, mules, susah bernapas , nyeri punggung, sering berkemih dan respon psikis yang di alami ibu hamil berupa depresi , stress, kecemasan dan gangguan tidur(Kemenkes RI, 2014)

Gangguan tidur banyak dialami pada ibu hamil terutama pada usia ke hamilan trimester III . wanita hamil mengalami kecemasan yang berakibat munculnya depresi dan kesulitan tidur atau insomnia .kesulitan tidur pada wanita hamil bisa berupa penurunan durasi tidur ibu hamil (wahyuni,2013). Ibu hamil trimester III adalah masa penentu untuk menyiapkan tubuh menghadapi persalinan.ibu hamil trimester III akan mengalami perubahan lebih berat dalam tubuh karena bayi tumbuh dengan pesat dan tubuh bergerak menuju persiapan untuk kelahiran sehingga focus latihan yang dilakukan adalah pada tulang belakang dan kekuatan serta keseimbangan panggul, baik otot, sendi tulang, ligam en(yesie, 2020).

Berdasarkan penelitian Sari (2019) dari data 34 orang ibu hamil trimester III dengan menggunakan Uji Wilcoxon. Kualitas tidur ibu hamil sebelum pemberian perlakuan didapatkan 59,5\% responden dengan kualitas tidur yang buruk. Setelah diberikan perlakuan yoga hamil terjadi peningkatan, dimana sejumlah $73 \%$ responden mengalami kualitas tidur yang baik. Ada pengaruh yoga hamil terhadap kualitas tidur pada ibu hamil trimester III (Sari,2019)

Berdas arkan penelitian Tria (2019) dari 26 orang ibu hamil trimester III dapat dilihat bahwa rata-rata kualitas tidur ibu hamil trimester III di mana sebelum melakukan senam hamil ada 22 orang ibu hamil yang mengalami kualitas tidur yang buruk dikarenakan rata-rata ibu hamil mengeluh merasakan nyeri pinggang belakang dan perut bagian bawah, ibu juga sering terbangung di malam hari untuk ke kamar mandi/ buang air kecil serta ibu meras akan kualitas 
e-ISSN 2774-4671

Vol. 1 Nomor 2

Tahun 2021

Hal. $61-71$
JID A N

JURNAL ILMIAH KEBIDANAN

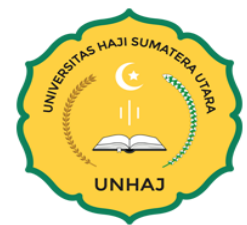

tidur yang kurang dan 4 orang ibu hamil mengalami kualitas tidur yang baik sedangkan setelah dilakukan senam hamil didapatkan hasil frekuensi meningkat bahwa 10 orang ibu hamil mengalami kualitas tidur buruk dikarenakan ibu masih merasakan nyeri pinggang maupun perut bagian bawah, terbangun di malam hari untuk ke kamar mandi/ BAK dan 16 orang ibu hamil mengalami kualitas tidur baik. (Tria ,2019)

Berdasarkan survey awal pada ibu hamil di UPTD Puskesmas Aek Loba Bulan Desember 2020 . Terdapat data 20 orang ibu hamil yang memeriksa kehamilanny a diantaranya terdapat 8 orang ibu hamil trimester III ada 5 orang ibu hamil yang mengikuti Prenatal yoga, ibu mengatakan sebelum mengikuti Prenatal yoga kualitas tidur ibu 4-5 jam, ibu mengatakan sering mengalami perasaan yang tidak nyaman, pegal dan tengang diseluruh bagian badan karena kurang istrahat. Mual dan sesak nafas, ibu juga mengatakan ada perubahan pada dirinya yaitu cepat emosi, mudah marah, merasa cemas, takut, dan depresi selama kehamilan. Setelah mengikuti Prenatal yoga ibu lebih merasa rileks, nyaman, perubahan-perubahan yang terjadi pada dirinya mulai berkurang, karena Prenatal yoga lebih memfokuskan perhatian pada ritme nafas, juga dapat meningkatkan aliran darah keseluruh tubuh.Sehingga dapat terjadi peningkatan kualitas tidur ibu sekitar 7-8 jam. Dan 3 orang ibu hamil trimester III yang tidak mengikuti Prenatal yoga mengatakan tidur malam hanya 4-5 jam dan tidak ada perubahan pada kualitas tidur ibu.

Berdasarkan uraian latar belakang diatas, maka peneliti tertarik untuk melakukan peneliti dengan judul "Pengaruh Prenatal Yoga dengan Kualitas Tidur Ibu Hamil Trimester III di UPTD Puskesmas Aek LobaTahun 2021.

\section{Metode Penelitian}

Desain dalam penelitian ini adalah Pre-eksperimental. Pre-eksperimental yaitu suatu rancangan penilitian yang digunakan untuk mencari sebab akibat dengan adanya keterlibatan penelitian dalam melakukan manipulasi terhadap variable. Rancangan penelitian yang digunakan pada penelitian ini adalah one group pre test post test design yang merupakan penelitian eksperimen dimana tidak menggunakan kelompok pembanding (control), namun sebelumnya kelompok tersebut sudah dilakukan observasi pre test sehingga peneliti dapat membandingkan perubahan setelah dilakukan eksperimen.

\begin{tabular}{|rrr|} 
Pre test & Perlakuan & Post test \\
\hline $\mathbf{0 1}$ & $\mathbf{X}$ & $\mathbf{0 2}$ \\
\hline
\end{tabular}

\section{Keterangan :}

\section{Gambar 1 Rancangan penelitian}

01 : Kualitas tidur ibu Hamil sebelum di beri Prenatal yoga

$\mathrm{X}$ : Pelaksanaan Senam Yoga

02 : Kualitas tidur Ibu Hamil Trimester III setelah di berikan prenatal Yoga

Populasi pada penelitian ini adalah semuaibu hamil trimester III yang akan mengikuti senam hamil di UPTD Puskesmas Aek Loba Tahun 2021 yaitu sebany ak 30 responden. Sampel 
yang digunakan adalah jumlah dari total populasi. Pada penelitian ini instrumen yang digunakan variable prenatal yoga adalah SOP prenatal yoga dan variabel kualitas tidur yaitu kuesioner dan observasi . Kuesioner ini terdiri dari 16 poin pertanyaan yang terdiri dari 7 komponen nilai yaitu kualitas tidur subjektif, latensi tidur, lama tidur malam, efisiensi tidur, gangguan ketika tidur malam, menggunakan obat-obat tidur, terganggunya aktisitas disiang hari. Ketujuh komponen tersebut dijumlahkan sehingga terdapat skor 0-21, kualitas tidur baik jika memiliki nilai PSQI <5 dan kualitas tidur buruk jika memiliki nilai PSQI >5 (Bus sey, 1988 dalam Khasanah 2012).

Instrumen penelitian dengan kuesioner Pittsburg Sleep Quality Indeks (PSQI) yang telah diuji validitas dan reabilitas oleh peneliti sebelumnya, maka kuesioner ini dinyatakan valid dan reliabel untuk digunakan dalam penelitian.

Tabel 1. Definisi Operasional

\begin{tabular}{cccc} 
Variabel & Alat Ukur & Skala & Skor/kategori \\
\hline 1. kualitas tidur & Kuisioner & $\begin{array}{c}\text { kualitas tidur baik } \\
>7 \text { jam } / \text { hari }\end{array}$ & PSQI $<5$ \\
\hline 2. Prenatal Yoga & observasi & $\begin{array}{c}\text { Kualitas tidur } \\
\text { buruk }<7 \text { jam } / \text { hari }\end{array}$ & PSQI $>5$ \\
\hline
\end{tabular}

\section{Hasil Dan Pembahasan}

Hasil

Berdasarkan hasil penelitian yang telah dilakukan terhadap 30 reponden, adapun karakteristik responden sebagai berikut :

Tabel 2 Karakteristik Responden di UPTD Puskesmas Aek Loba

\begin{tabular}{lccc}
\hline Karakteristik & Rincian & $\begin{array}{c}\text { Frekuensi } \\
(\mathbf{n})\end{array}$ & $\begin{array}{c}\text { Persentase } \\
(\mathbf{\%})\end{array}$ \\
\hline Umur & $<20$ tahun & 2 & 6,7 \\
& $20-35$ tahun & 25 & 83,3 \\
& $>35$ tahun & 3 & 10,0 \\
\hline Pendidikan & SD & - & - \\
& SLTP & 9 & 30 \\
& SLTA & 19 & 63,3 \\
& PT & 2 & 6,7 \\
\hline Pekerjaan & IRT & 24 & 80 \\
& PNS & 1 & 3,3 \\
& Swasta & 5 & 16,5 \\
\hline Agama & Islam & 26 & 86,6 \\
& kristen & 32 & 13,4 \\
& Protestan & - & - \\
& Hindu & - & - \\
& Budha & - & - \\
\hline
\end{tabular}




\begin{tabular}{|c|c|c|c|}
\hline Karakteristik & Rincian & $\begin{array}{l}\text { Frekuensi } \\
\text { (n) }\end{array}$ & $\begin{array}{c}\text { Persentase } \\
(\%)\end{array}$ \\
\hline \multirow{5}{*}{$\begin{array}{l}\text { Sumber Informasi yang pernah } \\
\text { diperoleh mengenai prenatal yoga }\end{array}$} & Majalah & - & - \\
\hline & Teman & - & - \\
\hline & Media Cetak & - & - \\
\hline & Tenaga Kesehatan & 3 & 10 \\
\hline & Media Elektronik & 2 & 6,7 \\
\hline Total & 30 & 100,0 & \\
\hline
\end{tabular}

Berdasarkan Tabel 2 dapat diketahui bahwa res ponden dalam penelitian ini sebagian besar berusia 20-35 tahun sebanyak 25 responden atau 83,3\%. Hal ini menunjukkan bahwa dari segi umur ibu di UPTD Puskesmas Aek Lobasebagian besar usia reproduktif. Kebanyakan ibu dengan pendidikan SLTA sebanyak 19 ibu atau 63,3\%. Hal ini menunjukkan bahwa rata-rata pendidikan ibu di UPTD Puskesmas Aek Loba, memiliki pendidikan sekolah lanjutan tingkat Atas. Diketahui bahwa responden dalam penelitian ini adalah sebagian besar tidak bekerja atau sebagai IRT yaitu sebanyak 24 responden atau $80 \%$. Hal ini menunjukkan bahwa dari segi pekerjaan ibu di UPTD Puskesmas Aek Loba sebagian besar tidak bekerja atau mengurus rumah tangganya. Kebanyakan ibu dengan beragama Is lam sebanyak 26 ibu atau 86,6\%. Hal ini menunjukkan bahwaratarata ibu di UPTD Puskesmas Aek Loba agama Islam. Kebanyakan sumber informasi tentang Prenatal yoga didapat dari petugas kesehatan sebanyak 3 ibu atau $10 \%$. Hal ini menunjukkan bahwa rata-rata ibu di UPTD Puskesmas Aek Loba mendapatkan sumber informasi tentang Prenatal yoga dari petugas kesehatan .

Tabel 3 Distribusi Frekuensi Responden berdasarkan penerapan senam yoga dalam kehamilan di wilayah kerja UPTD Puskesmas Aek Loba Tahun 2021

\begin{tabular}{ccc}
\hline Penerapan & Frekuensi & Persentase (\%) \\
\hline Pernah & 2 & 6,6 \\
Belum pernah & 28 & 93,4 \\
\hline Jumlah & $\mathbf{3 0}$ & $\mathbf{1 0 0}$ \\
\hline Data primer diperoleh pada tahun 2021 & &
\end{tabular}

Berdasarkan tabel 3 menunjukan bahwa dari 30 responden sebagian kecil responden menerapkan tentang senam yoga dalam kehamilan sejumlah 2 orang ibu hamil $(6,6 \%)$

Tabel 4 Distribusi Frekuensi Responden berdasarkan kesulitan tidur pada trimester III di wilayah kerja UPTD Puskesmas Aek Loba Tahun 2021

\begin{tabular}{ccc}
\hline Kesulitan tidur & Frekuensi & $\begin{array}{c}\text { Persentase } \\
(\boldsymbol{\%})\end{array}$ \\
\hline Ya & 26 & 86,7 \\
Tidak & 4 & 13,3 \\
\hline Jumlah & $\mathbf{3 0}$ & $\mathbf{1 0 0}$ \\
\hline Data primer diperoleh pada tahun 2021 & &
\end{tabular}


Berdasarkan tabel 4 menunjukan bahwa dari 30 responden hampir seluruh responden mengalami kesulitan tidur ketika kehamilan memasuki trimester III yaitu berjumlah 26 orang ibu hamil $(86,7 \%)$

Tabel 5 Distribusi Frekuensi kualitas tidut ibu hamil trimester III sebelum pelaksanaan senam yoga di UPTD Puskesmas Aek Loba Tahun 2021

\begin{tabular}{ccc}
\hline Kualitas tidur & Frekuensi & Persentase (\%) \\
\hline Baik & 4 & 13,3 \\
Buruk & 26 & 86,7 \\
\hline Jumlah & $\mathbf{3 0}$ & $\mathbf{1 0 0 , 0}$ \\
\hline
\end{tabular}

Data primer diperoleh pada tahun 2021

Berdasarkan table 5 menunjukan bahwa dari 30 responden hampir seluruh res ponden mempunyai kualitas tiduryang buruk yaitu sejumlah 26 orang ibu hamil $(86,7 \%)$

Tabel 6 Distribusi Frekuensi kualitas tidut ibu hamil trimester III sesudah pelaksanaan senam yoga di UPTD Puskesmas Aek Loba Tahun 2021

\begin{tabular}{ccc}
\hline Kualitas tidur & Frekuensi & Persentase (\%) \\
\hline Baik & 27 & 90 \\
Buruk & 3 & 10 \\
\hline Jumlah & $\mathbf{3 0}$ & $\mathbf{1 0 0 , 0}$ \\
\hline Data primer diperoleh pada tahun 2021 & &
\end{tabular}

Data primer diperoleh pada tahun 2021

Berdasarkan tabel 6 menunjukan bahwa dari 30 responden hampir seluruh responden mempunyai kualitas tiduryang baik yaitu sejumlah 27 orang ibu hamil (90\%)

Tabel 7 Distribusi Frekuensi pengaruh senam yoga terhadap kualitas tidur ibu hamil trimester III di UPTD Puskesmas Aek Loba Tahun 2021

\begin{tabular}{cccccccc}
\hline Variabel & Perlakuan & $\mathbf{N}$ & Mean & SE & SD & t & p-value \\
\hline Kualitas & Sebelum & 30 & 1,87 &, 063 &, 346 & 8,332 & 0,000 \\
tidur & Sesudah & 30 & 1,10 &, 056 &, 305 & &
\end{tabular}

Data primer diperoleh pada tahun 2021

Berdasarkan table 7 analisis statistik dengan menggunakan uji Paired T test diperoleh rata-rata sebelum prenatal yoga 1,87 dan setelah melaksanakan yoga menjadi 1,10 dan t 8,332 dengan bantuan SPSS 21 dengan tingkat signifikasi $\alpha=0,05$ diperoleh 
e-ISSN 2774-4671

Vol. 1 Nomor 2

Tahun 2021

Hal. 61 - 71

JURNAL ILMIAH KEBIDANAN

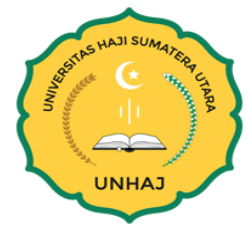

hasil $p=0,000$ yang berarti $p<0,05$ yaitu Ha diterima yang artinya ada pengaruh senam yoga terhadap kualitas tidur ibu hamil trimester III di wilayah UPTD Puskesmas Aek Loba.

\section{Pembahasan}

Kualitas tidur ibu hamil trimester III sebelum pelaksanaan senam yoga

berdasarkan hasil penelitian yang dilakukan pada 30 responden dengan memberikan

Quisioner PSQI sebanyak 18 soal berupa pertanyaan pada table 4.4 menunjukan bahwa dari 30

responden hampir seluruh responden mempunyai kualitas tidur yang buruk sejumlah 26 ibu hamil $(86,7 \%)$. Kualitas tidur itu sendiri meliputi 7 parameter yaitu kualitas tidur subjektif, latensi tidur, lama tidur malam ,efisiensi tidur,gangguan ketika tidur malam ,menggunakan obat tidur dan terganggunya aktifitas di siang hari.

Menurut Irma (2017) bahwa yoga pada kehamilan memfokuskan kenyamanan serta keamanan dalam berlatih sehingga memberikan banyak manfaat seperti meningkatkan energi, daya tahan tubuh, menghilangkan ketegangan otot, mengurangi keluhan fisik secara umum semasa kehamilan, seperti nyeri punggung, nyeri panggul, hingga pembengkakan bagian tubuh, membantu proses penyembuhan dan pemulihan setelah melahirkan, mens tabilkan emosi ibu hamil yang cenderung emosi, menguatkan tekad dan keberanian, menguatkan rasa percaya diri dan focus, membangun afirmasi positif dan kekuatan pikiran pada saat melahirkan. Menenangkan dan mengheningkan pikiran melalui relaksasi dan meditasi, memberikan waktu yang tenang untuk menciptakan ikatan batin antara ibu dan bayi, menanamkan rasa sabar dan bijaksana.

Hal ini jugasesuai dengan teori yessie (2020) Yoga dapat membantu ibu mempersiapkan pikiran dan tubuh ibu untuk kehamilan dan persalinan karena hal ini membantu ibu fokus, berkonsentrasi dan menjaga agar tubuh ibu tetap sehat. Postur tubuh yang dilatihkan pada yoga adalah postur tubuh yang mampu membantu ibu untuk menjaga tubuh tetap aktif dan lentur serta mampu membantu meminimalkan keluhan-keluhan umum yang sering dialami.

Kualitas tidur ibu hamil trimester III setelah pelaksanaan senam yoga

Berdasarkan hasil penelitian yang dilakukan pada 30 responden setelah pelaksanaan senam yoga di dapati pada table 4.5 dan menunjukan bahwa dari 30 responden sesudah dilakukan senam yoga hamir seluruh responden mempunyai kualitas tidur baik sejumlah 27 ibu hamil(90\%).

Menurut peneliti, peningkatan kualitas tidur yang baik ibu hamil trimester III setelah pelaksanaan prenatal yoga dikarenakan gerakan - gerakan senam yoga yang membawa energy positif untuk penyatuan setiap gerakannya, sehingga tubuh terasa lebih rilex, segar dan merasakan ketenangan dalam jiwanya.bagian rileksasi dari gerakan senam yoga sama halnya dengan meditasi dimana keheningan yang masuk di alam bawah sadar dan saat itulah stimulasi dari music dan suara pemandu membuat ketenangan, menghilangkan ketegangan dan afirmasi positif terbentuk dalam jiwa ibu hamil sehingga ibu hamil tidak merasakan kegelisahan, sulit tidur dan ketegangan pikiran. 
e-ISSN 2774-4671

Vol. 1 Nomor 2

Tahun 2021

Hal. $61-71$
$J \| D A N$

JURNAL ILMIAH KEBIDANAN

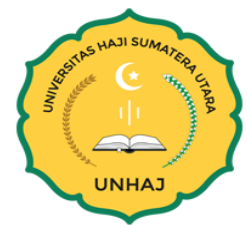

Menurut Rahmawati (2016) senam yoga bekerja menenangkan saraf simpatik pada saat bersamaan yoga merangsang system saraf parasimpatis yang memudahkan tubuh untuk beristirahat dan tidur, sehingga Nucleus Supra Chiasmatic (NSC) yang sebelumnya tidak bekerja normal dikarenakan saraf simpatik dan parasimpatik tidak bekerja dapat bekerja kembali dengan normal NSC akan kembali mengeluarkan hormone pengatur temperatur badan, kortisol, growth hormone, dll yang memegang peranan bangun tidur saat stimulasi cahaya terang masuk melalui mata, ketika malam tiba NSC akan merangs ang pengeluaran hormon melatonin sehingga orang mengantuk dan tidur. Ketika NSC berjalan normal maka NREM dan REM akan terpenuhi sehingga kualitas tidur penderita insomnia akan meningkat. Hal ini juga sesuai dengan teori menurut Febrina (2019) Yoga dalam kehamilan merupakan bentuk latihan yoga dan meditasi yang khusus dirancang untuk ibu hamil yang dapat menenangkan pikiran dan tubuh.

\section{Pengaruh senam yoga terhadap kualitas tidur ibu hamil trimester III}

Berdasarkan hasil penelitian yang dilakukan pada 30 responden dengan pemberian quisioner sebanyak 18 soal berupa pertanyaan yang dilakukan sebelum pelaksanaan senam yoga di dapati pada table 4.6 dan menunjukan bahwa dari 30 responden sebelumpelaksanaan senam yoga hampir seluruh responden mempunyai kualitas tidur buruk sejumlah 26 ibu hamil $(86,7 \%)$ dan sesudah dilakukan senam yoga hamir seluruh res ponden mempunyai kualitas tidur baik sejumlah 27 ibu hamil(90\%) sehingga dapat dilihat adanya peningkatan pada hasil pengukuran kualitas tidur sebelum dan sesudah dilakukan senam yoga dan dengan memperhatikan hasil uji statistic wilxocon yang menunjukan nilai signifikasi $\mathrm{p}(0,000)$ yang berarti $\mathrm{p}<0,05$ responden mempunyai kualitas tidur buruk sejumlah 26 ibu hamil $(86,7 \%)$ yaitu HI diterima yang artinya ada pengaruh senam yoga terhadap kualitas tidur ibu hamil trimester III di wilayah UPTD Puskesmas Aek Loba. Dengan demikian, dapat disimpulkan bahwa H0 ditolak dan Ha diterima. Peningkatan kualitas tidur yang di dapat sesudah pelaksanaan senam yoga selama $4 \mathrm{x}$ dalam 14 hari hal ini dibuktikan dengan post test no 5.

Menurut peneliti, peningkatan kualitas tidur ibu hamiltrimester III di akibatkan oleh meningkatnya rasa nyaman, tenang dan damai setelah pelaksanaan senam yoga karena ketika tubuh melakukan gerakan terbimbing dan meditasi, erotis yang membawa oksigen ke dalam darah menuju otak semakin lancar sehingga perasaan tubuh yang segar, ketenangan, kemudahan berkonsentrasi dan kenyamanan ketika beristirahat tercipta.

Berdasarkan penelitian Sari (2019) dari data 34 orang ibu hamil trimester III dengan menggunakan Uji Wilcoxon. Kualitas tidur ibu hamil sebelum pemberian perlakuan didapatkan 59,5\% responden dengan kualitas tidur yang buruk. Setelah diberikan perlakuan yoga hamil terjadi peningkatan, dimana sejumlah $73 \%$ responden mengalami kualitas tidur yang baik. Ada pengaruh yoga hamil terhadap kualitas tidur pada ibu hamil trimester III.

Hal ini juga sesuai dengan teori menurut Shindu (2014) Masa kehamilan merupakan saat istimewa seorang wanita dengan harapan kelahiran yang lembut, nyaman, dan membahagiakan. Berlatih yoga pada masa ini merupakan salah satu solusi self help yang akan menunjang proses kehamilan, kelahiran, dan bahkan pengas uhan anak. Yoga bagi kehamilan 
e-ISSN 2774-4671

Vol. 1 Nomor 2

Tahun 2021

Hal. 61 - 71
$J \| \mathrm{DAN}$

JURNAL ILMIAH KEBIDANAN

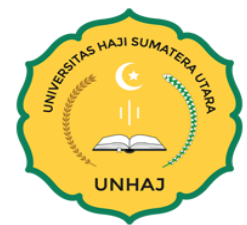

memfokuskan perhatian pada ritme napas, mengutamakan kenyamanan serta keamanan dalam berlatih sehingga memberikan manfaat.

\section{Kesimpulan}

Berdasarkan hasil penelitian yang diperoleh dengan analisis data dan pengujian hipetesis, maka dapat ditarik kesimpulan, sebelum dilaksanakan senam yoga menunjukkan hampir seluruh responden mempunyai kualitas tidur yang buruk sejumlah 26 orang ibu hamil $(86,7 \%)$. Sesudah dilaksanakan senam yoga menunjukkan hampir seluruh responden mempunyai kualitas tidur yang baik sejumlah 27 orang ibu hamil (90\%) dan Ada pengaruh kualitas tidur ibu hamil trimester III setelah dilaksanakan senam yoga menunjukkan hampir seluruh responden mempunyai kualitas tidur yang baik Hal ini ditunjukkan dengan hasil uji hasil uji statistic wilxocon yang menunjukan nilai signifikasi $p(0,000)$ yang berarti $p<0,05$. Dengan ini dapat disimpulkan bahwa_Ha diterima.

\section{Refrensi}

Arief, R. (2018) Departemen Pulmonologi dan ilmu kedokteran respirasi.Jakarta: FKUI-SMF Paru RSUD Persahabatan Jakarta.

Febrina, O. (2019)Modul Nande Prenatal Yoga,Medan.

Hidayat, A. (2017) Metodeologi Penelitian. diperoleh dari Statistikian.com

Hamidah, T . ( 2019 ) Senam Hamil untuk meningkatkan durasi tidur ibu hamil trimester III .Jakarta: http:jurnal.SMART Kebidanan.

Irma, S.(2017)Pengaruh Senam Yoga terhadap kualitas tidur ibu hamil trimester III.Jombang.Sekolah Tinggi Ilmu Kesehatan Citra Medika Jombang.

Kemenkes RI, (2014) Pegangan Fasilitas Kesehatan Ibu Hamil . Jakarta: Kementrian Republik Indonesia.

Lumban Tobing, SM. (2000) Neurologi klinik pemeriksaan fisik dan mental . Jakarta : Balai Penerbit FK UL.

Maulani, M.F, (2018) Pengaruh Rebusan Daun Pepaya Terhadap Intensitas Nyeri Haid Pada Siswi SLTP. Jurnal Kesehatan STIKES WIDIYA HUSADA Semarang. Vol. 5. nomor 3.

Nugroho, T. (2019) Asuhan Kebidanan 1 . Jogjakarta : Nuha Medika

Notoatmodjo, (2010) Metodologi Penelitian Kesehatan. Jakarta : Rineka Cipta.

Prawiharjo, S. (2016) Ilmu Kebidanan Edisi Keempat, Cetakan Kelima.

Jakarta : Tridasa Printer Ilmu Kandungan, Edisi Keempat, Cetakan Keempat. Jakarta : Tridasa Printer.

Rianto, A. (2019) Aplikasi Metodologi Penelitian Kesehatan. Yogyakarta: Nuha Medika, hlm. 216

Sidhu, P. (2014) Yogauntuk kehamilan. Bandung: PT Mizan Pustaka.

Sari . ( 2019 ) Pengaruh Yoga Hamil terhadap kualitas tidur ibu hamil Trimester III di Klinik Pratama Asih Waluyo Jati. Jati: http:jurnalhttp://e-journal.sarimutiara.ac.id/index.php/kesehatan. 
e-ISSN 2774-4671

Vol. 1 Nomor 2

Tahun 2021

Hal. $61-71$

\section{JURNAL ILMIAH KEBIDANAN}

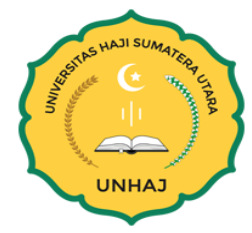

Wahyuni. (2013) Manfaat Senam Hamil untukmeningkatkan durasi tidur ibu hamil trimester III .Surakarta: http:jurnal Kesehatan Masyarakat.Universitas Muhammadiyah Surakarta.

Sri. (2013) Efektivitas Yoga Terhadap Kualitas Tidur Ibu Hamil. Riau: http:jurnal Sridelimaharahap@gmail.com. Universitas Riau

Tria, A . (2019) Pengaruh Senam Hamil terhadap kualitas tidur ibu hamil Trimester III di Wilayah kerja Puskesmas Ratu Agung Kota Bengkulu.Bengkulu: http:jurnal.strada.ac.id/jqwh|Email:jqwh@strada.ac.id

Yesie, A. (2020) Prenatal Gentle Yoga . Semarang: Pustaka Utama 